O eixo e a roda, Belo Horizonte, v.25, n.1, p. 87-108, 2016

\title{
A Rosa is a rose is arose: avaliando traduções de Grande sertão: veredas para 0 inglês
}

\section{A Rosa is a rose is arose: evaluating translations of Grande sertão: veredas to English}

Caetano Waldrigues Galindo

Universidade Federal do Paraná (UFPR), Curitiba / Brasil

cwgalindo@gmail.com

Resumo: $\mathrm{O}$ texto pretende apresentar o esboço de uma proposta de avaliação de resultados de tradução literária, em certa medida nos moldes da proposta de Paulo Henriques Britto (2002) para a poesia. A partir disso, o objetivo é ressaltar a diferença entre duas traduções para o inglês de Grande sertão: veredas, de João Guimarães Rosa (Taylor \& Onís, 1963; Entrekin, em curso) a partir de uma breve exposição das "singularidades" do original: daquilo que Meschonnic (2010) poderia chamar de "marcado".

Palavras-chave: tradução de prosa; análise formal do texto literário.

Abstract: The paper intends to present the outline of a model to comparatively evaluate the results of translations of literary prose; in certain senses this model is tributary to the proposal made by Paulo Henriques Britto (2002) in relation to poetic translation. After that, we try to confront two English translations of Grande sertão: veredas by João Guimarães Rosa (Taylor \& Onís, 1963; Entrekin, in progress) with the results of a brief exposition of the "singularities" found in the original: of those things Meschonnic (2010) could have seen as "marked".

Keywords: prose translation; formal analysis of the literary text. 
Recebido em 8 de março de 2016. Aprovado em 20 de junho de 2016.

Os comentários e as análises a respeito da tradução de prosa literária tendem a se ver em alguma medida privados do grau de "objetividade" (qualquer que seja ele) que pode embasar as leituras de traduções poéticas. A primeira razão dessa eventual discrepância é, obviamente, a extensão dos exemplos mais típicos de textos prosaicos e poéticos.

Não precisamos discutir aqui a labilidade desta fronteira (como de tantas outras), na medida em que é bastante transparente a existência de textos prosaicos autossuficientes, autônomos, merecedores de análise por si sós, que acabam, no entanto, por ter extensão (por vezes consideravelmente) menor que a de muitos poemas. Mas resta o fato de que em sua realização mais típica pensamos na obra prosaica como algo que se desenvolve ao longo de um contínuo temporal de extensão maior, mais dilatada, distendida. Pensamos, além disso (e corretamente), que boa parte dos efeitos singulares e centrais da produção e da fruição da prosa literária de (maior ou menor) qualidade, são não apenas decorrências cegas dessa maior extensão temporal, mas, na verdade, maneiras mais ou menos profundas e sofisticadas de se lidar com esses mesmos fatores, de se beneficiar deles e de imputar a eles um peso estrutural maior e mais relevante.

Não precisamos necessariamente encampar toda a estética jamesiana do romance (nem aceitar, como, no entanto, acho que acabo aceitando, seu "chauvinismo do romance", como um crítico recente pretende caracterizá-lo) ${ }^{1}$. Mas se de fato consideramos que o romance possa ser algo mais que um "monstro frouxo", ${ }^{2}$ temos que levar em consideração que as simetrias, os espelhamentos, os jogos de encaixe, de framing e de babushkas que dão a esta forma literária sua solidez como construto formal têm de se dar, talvez não apenas ali, mas também nessa longue durée, com o perdão da apropriação enviesada.

No romance, o que "rima" por vezes rima a centenas de páginas de distância.

\footnotetext{
${ }^{1}$ Cf. ROBSON, 2016.

${ }^{2}$ Novamente, sem considerarmos que Guerra e paz precisa estar nessa categoria, como supõe James.
} 
No romance o que se estabelece como o equivalente do desvio em relação à pauta métrica tácita ou declaradamente estabelecida é possivelmente também da ordem da hora-leitura, não do minuto.

Mas não podemos desconsiderar a relevância de uma segunda possível razão para essa ligeira leviandade (redundância intencional) na análise formal da narrativa prosaica, do conto, do romance, da prosa tout court. E ela se deve, pura e simplesmente, à inexistência de um protocolo convencional de análise, mesmo que se tratasse de um protocolo questionável e relativizável, nos moldes do ferramental desenvolvido desde a Vita nuova de Dante Alighieri pela tradição retórico-poética.

A narratologia até hoje não me parece ter desembocado definitivamente em uma via univocamente codificada de estudo formal, de imbricação de pele e carne, de superfície e conteúdo, de prosa e prosa. A prosaística bakhtiniana, por sua vez, é por sua própria natureza avessa a tais formulações; é case-specific: é generalizante. E mais uma vez nos vemos frequentemente reduzidos, no que se refere à interface texto-obra centralmente cara a toda a empresa tradutória, ao "reaproveitamento" de noções de análise estilística fundamentalmente poéticas, elaboradas a partir de textos e categorias poéticas e destinadas, ainda que somente por isso, à análise de uma forma literária constituída (segundo os mesmos tennets da narratologia ou da leitura bakhtiniana) de modo fulcralmente oposto ao da prosa de ficção; uma forma destilada de uma visão de linguagem-mundo que no fundo the é oposta.

\section{Eppure...}

Continuamos a fazer crítica de tradução (na imprensa, especialmente), e acima de tudo, em termos quantitativos, continuamos a fazer crítica de tradução de prosa; continuamos a elencar méritos e deméritos relativos desta e daquela tradução; continuamos a elogiar a contribuição que determinada tradução teria dado ao futuro de certa obra na sua nova cultura ao mesmo tempo em que lamentamos a influência deletéria, por vezes quase que a condenação a que certa outra tradução pôde relegar um livro inteiro, trancado assim na sua fonte: cerceado.

O objetivo deste ensaio é de fato ensaiar (e pouco mais que isso, neste momento) uma leitura formal da tradução de prosa literária que, ainda que não possa se arvorar o grau de "objetividade" e de detalhismo (ao menos dentro dos limites de espaço que cabem aqui) a que Paulo Henriques Britto pretendia chegar no seu "Para uma análise objetiva da 
tradução de poesia" (2002), ${ }^{3}$ possibilite o embasamento de comentários que, por sua vez, alicercem a possibilidade de uma análise contrastiva de (sim) méritos, qualidades, efetividades, eficiências.

Para isto vou me servir do texto brasileiro classicamente mais discutido no mundo da tradução, Grande sertão: veredas. Ou de apenas um parágrafo: o primeiro.

Partir de um texto brasileiro me permite acreditar (eu, falante nativo de português, e apenas de português) partir também de uma análise mais sólida e justificável do texto-base, ou da base do que viria a ser o "texto-primeiro", ${ }^{4}$ texto-fonte, para a partir daí encarar com mais segurança o território sempre móvel da língua estrangeira.

Partir apenas de um parágrafo, conquanto seja grande o parágrafo, é uma tentativa de dar conta daquele primeiro obstáculo para a análise formal que pretendo expor. Quanto ao segundo, dentro dos limites deste ensaio, pretendo em alguma medida "importar" não as categorias (necessariamente) nem o método (rigorosamente), mas como que o espírito e o "protocolo" analítico exemplificado pelo texto de Britto (2002).

Grosso modo, o que se pretende aqui é partir, portanto, de uma leitura quase quantitativa, que sinalize no original os tipos de "desvios", "singularidades", de tudo que seja "marcado", nos termos de Méchonnic (2010), e seus locais, e que busque confrontar essa quase-contabilidade com os resultados advindos de leitura semelhante (ainda que mais sintética) das traduções propostas, para, a partir disso (essa é, e sempre

\footnotetext{
${ }^{3}$ Pretensão efetivamente "bancada" por dezenas de análises realizadas por ele em outros textos e em situação de palestra/conferência...

${ }^{4}$ Tenho que remeter essa discussão, se for para remetê-la ainda a algum lugar, a um texto que ainda elaboro; mas a distinção fulcral aqui se apoia em um paralelo com a composição musical (texto-base): existente, irrealizado, intangível, acessível apenas a partir da interpretação individual (texto-primeiro, no caso de uma estreia; texto, apenas em outras situações): existente, realizada, tangível, acessível e via de acesso à composição. O que me interessa nessa visão é que ela tem a capacidade de relativizar (malgrado a não relativização da belatedness de qualquer tradução se considerada em relação com seu original) o estatuto hierárquico de "original" e tradução, vistos ambos como realizações de um material de base que, geneticamente, surge, é fato, junto com o texto-primeiro, mas que é em considerável medida depreensível e desprendivel dele, como o prova a "estabilidade" do texto em suas versões traduzidas: sua "mesmacoisidade".
} 
deverá ser, uma análise-meio), tentar entender as possibilidades de uma triagem comparativa de triunfos e fracassos, parciais ou totais.

Outra singularidade (talvez uma necessidade real e próxima de incontornável no caso de uma proposta dessa natureza) é o fato de estar lidando não com uma, mas com duas traduções do mesmo texto. Neste caso, uma tradução (a primeira para a língua inglesa, de 1963), repetidamente vilipendiada, e uma outra (ainda inédita ${ }^{5}$, que talvez tenha maior potencial de sucesso em termos estritamente literários.

A distância temporal, e a própria belatedness da segunda tradução - que nesse caso pôde se beneficiar não apenas da experiência e dos resultados de seus antecessores, mas também de toda a fortuna crítica (basicamente negativa) que se construiu a partir dela -, são elementos que têm de fazer parte (ainda que seja apenas num disclaimer desta natureza) do processo de análise comparativa.

\section{$* * *$}

É necessário dizer que entro nessa discussão como tradutor e como interessado na prática e na teoria da tradução. Estou muito longe de sequer conceber a possibilidade de me dar ares de especialista ou de scholar no que se refere à obra de Guimarães Rosa e aos complexos processos de sua tradução e recepção. E talvez seja até melhor assim, para uma proposta preliminar como esta. Entro no texto de Rosa como "leitor brasileiro típico" dos dias de hoje (ou ao menos como leitor que bem tipifica aqueles que se aproximariam de sua obra), intencionalmente sem buscar dados, trivia e elucidações mais arcanas e mais à clé; informações que são obviamente relevantes para os leitores mais especializados e, também, para os tradutores, mas não necessariamente centrais (como processo) para os leitores seja do texto original, em 2016, seja das traduções dele derivadas, legíveis e lidas por versões (indivíduos) equivalentes em suas respectivas culturas desse "leitor-modelo" aqui projetado.

Ou seja, em maior detalhe: não quero propor que a investigação fina, ilimitada do texto-fonte não tenha valor como leitura e não gere valor

\footnotetext{
${ }^{5}$ A segunda tradução, de Alison Entrekin, teve seu primeiro excerto publicado ainda há pouco, na revista Words Without Borders.
} 
na tradução. ${ }^{6} \mathrm{O}$ que apenas me interessa aqui (e neste momento, apenas aqui) é a leitura do texto como pano, como pele, como superfície tratável e legível, nos moldes de uma boa leitura, bem formada, mas ainda não "de especialista", que no entanto reconhece sempre que se beneficiará tacitamente, no caso das traduções, de todo o trabalho dessa natureza que possa ter sido feito. Mas é importante, para o tipo de leitura que posso pretender "emular" aqui, que seja tácita essa percepção.

Feitas essas ressalvas, vamos ao original:

- Nonada. Tiros que o senhor ouviu foram de briga de homem não, Deus esteja. Alvejei mira em árvores no quintal, no baixo do córrego. Por meu acerto. Todo dia isso faço, gosto; desde mal em minha mocidade. Daí, vieram me chamar. Causa dum bezerro: um bezerro branco, erroso, os olhos de nem ser — se viu —; e com máscara de cachorro. Me disseram; eu não quis avistar. Mesmo que, por defeito como nasceu, arrebitado de beiços, esse figurava rindo feito pessoa. Cara de gente, cara de cão: determinaram - era o demo. Povo prascóvio. Mataram. Dono dele nem sei quem for. Vieram emprestar minhas armas, cedi. Não tenho abusões. O senhor ri certas risadas... Olhe: quando é tiro de verdade, primeiro a cachorrada pega a latir, instantaneamente - depois, então, se vai ver se deu mortos. O senhor tolere, isto é o sertão. Uns querem que não seja: que situado sertão é por os campos-gerais a fora a dentro, eles dizem, fim de rumo, terras altas, demais do Urucuia. Toleima. Para os de Corinto e do Curvelo, então, o aqui não é dito sertão? Ah, que tem maior! Lugar sertão se divulga: é onde os pastos carecem de fechos; onde um pode torar dez, quinze léguas, sem topar com casa de morador; e onde criminoso vive seu cristo-jesus, arredado do arrocho da autoridade. O Urucuia vem dos montões oestes. Mas, hoje, que na beira dele, tudo dá — fazendões de fazendas, almargem de vargens de bom render, as vazantes; culturas que vão de mata em mata, madeiras de grossura, até ainda virgens dessas lá há. $\mathrm{O}$ gerais corre em volta. Esses gerais

\footnotetext{
${ }^{6}$ Ainda está para chegar (e torço muito para que não chegue) o dia em que essas propostas possam verossimilmente partir de um tradutor de Ulysses.
} 
são sem tamanho. Enfim, cada um o que quer aprova, o senhor sabe: pão ou pães, é questão de opiniães... O sertão está em toda parte (ROSA, 1956, grifos meus).

O que proponho a seguir é uma primeira-leitura de tradutor. Uma vista d'olhos que destaque no texto o que no texto é desvio, desmando e comando, alteração, marca. Os momentos, e o tipo dos momentos, em que a tradução deveria responder "à altura", vertendo o marcado pelo marcado. Para facilitar essa leitura, eis o texto mais uma vez, divido em períodos e com marcas em negrito para o que se podem considerar desvios bem marcados, e em itálico para singularidades menos "violentas". Repetindo sempre que se trata de uma análise pessoal que pretende atingir o grau de leitura de um bom leitor de literatura brasileira. Nada mais. E frisando que, como bem sabe justamente esse parágrafo, opiniães sempre hão de poder divergir.

\section{1. "- Nonada."}

Muito se fala da primeira palavra do livro. Desde o folclore de que seria um "neologismo" até a informação de que seria uma palavra como qualquer outra, apenas por constar de dicionários. No fundo, hoje, poucos leitores brasileiros teriam familiaridade com ela.

2. "Ø Tiros que o senhor ouviu foram de briga de homem não, Deus esteja."

Uma omissão de artigo definido (a primeira de uma imensidade ao longo de todo o livro; logo, marca maior), além da posição final da negação (comum na oralidade do nordeste, mas marcada em termos de norma padrão brasileira contemporânea) e da imprecação "Deus esteja": nada estranha em demasia, mas definitivamente singular, desviante.

3. "Alvejei mira em árvores no quintal, no baixo do córrego."

A expressão "alvejar mira" causa certo ruído, mas nada mais que isso. "No baixo do córrego" é saboroso, sim, mas nada problemático.

4. "Por meu acerto."

Aqui, apesar de ainda podermos estar dentro de uma verossímil esfera de regionalismo plausível (e essa confluência de marcas pode muito bem servir para sublinhar a serventia dessa abordagem "planificadora"), temos um enviesamento definitivo do que seriam as maneiras mais retas de se fornecer a informação no Brasil. Seja pela ausência do artigo, seja pela substantivação em "acerto". Fora isso, entramos em outro terreno, o da tendência que já se detecta no parágrafo e vai se confirmar no livro 
todo de uma dinâmica como que de reticências, onde a dimensão dos períodos se quebra em unidades cada vez menores (um sintagma de tamanho X, seguido de outro, ou outros, com um terço de seu tamanho, por exemplo, frequentemente como que "arrematados" por um sintagma bem menor, muitas vezes em sentença isolada). Esse "ritmo", quase uma pauta métrica sem metro, onde os pesos são todos "relativos", foi a primeira marca de estilo que eu mesmo percebi no livro, no primeiro contato com ele.

5. "Todo dia isso faço, gosto; desde mal em minha mocidade."

O mesmo se dá na primeira parte deste período, antes do ponto e vírgula, onde, além disso, há a marcada inversão de sujeito-objeto e mais uma supressão, agora de pronome sujeito (e não preciso lembrar que, em se tratando de um skaz, da encenação de uma narrativa oral, e de um skaz em uma variante do português do Brasil, qualquer supressão de pronome sujeito é desvio.) O segundo "hemistíquio" novamente nos põe no domínio do marcado transparente: qualquer bom leitor brasileiro vai entender, vai perceber certo grau de estranhamento, vai reconhecer um certo sabor de oralidade naquela expressão. Uma marca regional e de caráter (personagem: skaz).

6. "Dai, Ø vieram me chamar."

Além da marca clara de oralidade no "daí" e de nova supressão de pronome sujeito, nada de maior monta.

7. “Ø Causa dum bezerro: um bezerro branco, erroso, os olhos de nem ser — se viu —; e com máscara de cachorro."

A supressão da preposição (regionalismo, oralidade) abre caminho para todo o estranhamento (devidamente arrematado de novo por um afterthought) da descrição do bezerro, a serviço, claro, dos meandros e quase que da recusa de Riobaldo em "encarar" diretamente a tarefa de descrição de algo que lhe dá medo. Sua linguagem se arrepia. O estranho adjetivo "erroso"... o que seriam os "olhos de nem ser"? E, grau último dessa dissolução, desse afastamento, qual a função sintática daquele "se" entre travessões?

8. "Me disseram; eu não quis avistar."

Dois staccatos depois do jorro e da confusão final, mais o algo singular uso do verbo "avistar" que, mais do que mero desvio, é marca claríssima de certa "hipercorreção", de certa pretensa pompa que é de um lado típica de Riobaldo e, de outro, motivada pelo estatuto aparente de seu interlocutor. 
9. "Mesmo que, por defeito como nasceu, arrebitado de beiços, esse figurava rindo feito pessoa."

Mais uma vez, a dificuldade de enfrentar a imagem gera distorção sintática ("por defeito como nasceu"), além de uma construção um tanto singular em "arrebitado de beiços" e de mais um uso algo deslocado e talvez hipercorreto, agora do verbo "figurar". O emprego de "feito" em lugar de "como" é regionalismo/diacronismo bem conhecido.

10. "Cara de gente, cara de cão: determinaram - era o demo."

O interesse do período está no ritmo, nas oposições, no preciosismo de "determinaram" e, claro, no primeiro dos termos eufêmicos para o demônio no livro.

11. "Povo prascóvio. Ø Mataram."

"Prascóvio" é dicionarizado, mas pouco frequente, e estranho na boca de Riobaldo. Mais uma omissão de pronome sujeito.

12. "Dono dele nem sei quem for."

Omissão do artigo, certo enviesamento sintático da ordem padrão dos constituintes e o curioso uso de uma forma subjuntiva por outra. Riobaldo e suas lidas com a alta gramática.

13. "Vieram emprestar minhas armas, cedi."

Aqui o maior interesse (a omissão do sujeito é quase imperceptível) é a ambiguidade do verbo "ceder": a manutenção dos sentidos de "entregar" e de "aquiescer" seria de extremo interesse em tradução.

14. "Não tenho abusões."

Já se cria uma dinâmica de supressão do sujeito. Fora isso, “abusão" é também dicionarizado, mas pouco frequente (além de ser a palavra, por pluralizada aqui, que possivelmente faz Riobaldo pensar nos "pães" de logo depois... amarração interna). E vale registrar que os dois sentidos básicos daquela "abusão" sublinham a ambiguidade de "ceder" logo atrás: de um lado, "superstições" e, de outro, "ilusões": ou seja, seria inútil negar as armas, outro as emprestaria.

15. "O senhor ri certas risadas..."

A frase, claro, é importante, marcando (vindo exatamente no meio das 28 sentenças) a virada do parágrafo, o abandono da história do bezerro diante de uma primeira reação do interlocutor. Registre-se já, apesar de não se tratar de qualquer desvio necessário do padrão literário brasileiro e nem mesmo das convenções de uma interação encenada como a de Riobaldo com seu interlocutor, que o uso de "o senhor" causará problemas para quase todas as traduções. Nem mesmo nós, brasileiros, 
somos capazes de descrever satisfatoriamente o jogo extremamente sofisticado de tudo que se codifica em seus vários usos possíveis nesse sintagma. Claro, também, que "rir certas risadas" pode não ser gongórico, mas também não é cristalino, não é "primeira escolha".

16. "Olhe: quando é tiro de verdade, primeiro a cachorrada pega a latir, instantaneamente - depois, então, se vai ver se deu mortos."

Todo o lado "cheio de dedos" de Riobaldo se esvai num período (ou dois) mais longo e sintético (em termos de andamento retórico: ele, agora sim, explica e relativiza o "temor" do interlocutor), marcado apenas por putativos e plausíveis índices de oralidade e regionalismo ("pegar a latir", "ver se deu mortos" e mesmo aquele "depois, então,"), onde se engasta o quase beletrismo daquele longo "instantaneamente".

17. "O senhor tolere, isto é o sertão."

O ligeiríssimo enviesamento do uso de "tolere" onde "aceite" seria mais recomendável é típica graça riobaldiana.

18. "Uns querem que não seja: que situado sertão é por os campos-gerais a fora a dentro, eles dizem, fim de rumo, terras altas, demais do Urucuia."

E ele, a partir daqui, se lança na famosa e algo enlevada discussão do sertão, de o que é o sertão. E é interessante ver como a partir desse ponto o o quê narrado (o estranho caso do bezerro, que puxou o primeiro momento da conversa) deixa, de um lado, de ter tanto apelo narrativo e, de outro, de ser algo que Riobaldo quer de alguma maneira tocar apenas com a ponta dos dedos; e agora, com um assunto mais leve, menos incômodo e, talvez por isso mesmo, menos importante enquanto conteúdo tradicionalmente "informável”, os desvios linguísticos deixam de ser leves marcas de oralidade ou de personalidade ou demonstrações quase que de recalques e ocultações psicológicas e passam a se configurar algo mais próximo de ludismo, de uma retórica poética de encanto e de encantamento: de sedução. A partir daqui (e esse período já o demonstra perfeitamente), livre do assunto espinhoso que o incomodava, Riobaldo parece se divertir mais com o texto, estar mais à vontade com a invenção. Daí o paralelismo de "que não seja" e "que situado", ambos dependentes sintaticamente do verbo "querer"; daí o quase idiossincrático uso de "situado" por "propriamente dito", talvez; daí, de novo, o paralelismo de "a fora", grafado como duas palavras, e "a dentro", possível fruto de certa desleitura de "afora"; daí a recusa, de novo personalíssima, de fundir o artigo de "os campos gerais" com a preposição; daí as reticências 
rítmicas finais, onde a semântica se torna cada vez menos referencial e culmina no lindo modo de dizer torto ${ }^{7}$ que é aquele "demais do Urucuia".

19. "Toleima."

E, de novo, isso tudo se vê como que encapsulado numa retomada de apenas uma palavra, dicionarizada, é verdade, mas ainda muito marcada. sertão?"

20. "Para os de Corinto e do Curvelo, então, o aqui não é dito

O espírito polemizador de Riobaldo o leva agora a argumentar quase que apenas retoricamente (seu interlocutor estaria em posição de se manifestar?). E registre-se a substantivação de "aqui" e a curiosa construção que ao mesmo tempo usa um verbo possível em um lugar improvável e evoca outra, que seria mais clara com "o dito sertão". A se registrar aqui também o fato de o texto não escolher grafar "pra" ou “p'ra”. O registro de oralidade de Guimarães Rosa aqui está, via de regra, em outros lugares.

21. "Ah, que tem maior!"

E o espírito do skaz chega a seu ponto mais alto, com marcas de oralidade que, novamente, não precisam ser representações gráficas de pronúncias, nem apelos a regionalismos mais violentos. A construção é apenas, e perfeitamente, a ideal representação de uma frase brasileiríssima.

22. "Ø Lugar sertão se divulga: é onde os pastos carecem de fechos; onde um pode torar dez, quinze léguas, sem topar com casa de morador; e onde $\varnothing$ criminoso vive seu cristo-jesus, arredado do arrocho da autoridade."

E ele segue, com mais uma supressão de artigo definido (ou indefinido...), o regionalismo do uso de "carecer" e de "torar" (perfeitamente corrente no meu português sulista também), mais uma supressão de artigo diante de "criminoso" e a semântica razoavelmente clara, mas tortuosa de "cristo-jesus". Sem contar que no sintagma final, além do regionalismo tanto de "arredado" quanto de "arrocho", temos o primeiro uso claro de aliterações e assonâncias óbvias, quase tematizadas. Riobaldo de, fato, voa mais longe aqui.

23. "O Urucuia vem dos montões oestes."

\footnotetext{
${ }^{7}$ Penso no roseaníssimo poema de Emily Dickinson que se abre por "tell all the truth, but tell it slant" (diga a verdade toda, mas diga torta) (Tradução minha).
} 
Além da bela "pausa" que se intui antes da abertura do período, sua maior marca é a adjetivação de "oeste", que quase não nos faz perceber a oralidade já presente naquele "montões".

24. "Mas, hoje, que na beira dele, tudo dá - fazendões de fazendas, almargem de vargens de bom render, as vazantes; culturas que vão de mata em mata, madeiras de grossura, até ainda virgens dessas lá há."

O uso daquele "que" com sentido de "quando" (ou mesmo de "já que") é uma assinatura brasileira, e mais uma sutil e eficiente marca não caricata de oralidade. O "tudo dá", além de no mínimo "informal" também tem a quase inevitável ressonância da Carta de Caminha. E a definição do que "dá" nessa região a princípio erma e estéril, também "dá" corpo ao que será o maior período de todo o parágrafo, sublinhando ainda mais a centralidade desse "voo" retórico de Riobaldo, marcada ainda mais pelas aliterações e rimas e pela sequência de pelo menos três pés métricos anapésticos entre "fazendões" e "bom". A qualificação embutida no que seria um "fazendão" de uma fazenda é clara, hoje, em meio urbano, para qualquer falante de português brasileiro, mas nem por isso mais facilmente definível e "glosável"; esse mesmo falante, no entanto, teria quase que certamente que recorrer a um dicionário para encontrar aquelas "almargens de vargens", que no fundo descobriria que quase constituem uma redundância semelhante à dos "fazendões de fazendas". De novo o ritmo da contraposição de células maiores a fechos mais breves se estabelece com "as vazantes", que aqui tem sublinhado seu valor explicativo, mas, curiosamente, não encerra a enumeração: como que a demonstrar a fertilidade da cornucópia do sertão e da retórica do sertanejo, Riobaldo retoma o que parecia uma lista encerrada, que ainda inclui aquele elíptico e algo telegráfico "madeiras de grossura" e a violenta elipse (possivelmente de "terras": ou será referência anafórica àquelas "vargens"?) por trás de "dessas lá há", que ainda se dá ao luxo de encerrar o enlevo poético com uma quase grotesca cacofonia e uma anástrofe bem marcada em "lá há".

25. "O gerais corre em volta."

A singularização de "gerais", recurso tradicional ainda que, claro, algo desviante, soma-se ao uso totalmente informal de "corre".

26. "Esses gerais são sem tamanho."

E na breve sentença seguinte (ainda estamos no padrão vagamente "dactílico" que parece reger a distribuição da extensão dos períodos) 
a palavra aparece de novo tratada como plural, marca reforçada pela presença justamente daquele artigo definido tantas vezes eliminado.

27. "Enfim, cada um o que quer aprova, o senhor sabe: pão ou pães, é questão de opiniães..."

De novo certo hipérbato na sintaxe do que se segue ao esperado “enfim”, e que se verá espelhado, reforçado e reduplicado no lapidar "pão ou pães" que, além de poder ter relação com a pluralização anterior de "abusão", ilustra quase como numa punchline o espírito jocoso e, por que não, assumidamente metalinguístico do texto.

28. "O sertão está em toda parte."

Se falamos de uma dinâmica de frases/sintagmas curtos que decorrem de trechos maiores, nada mais adequado que terminar assim, de maneira seca, enxuta e, diga-se de passagem, quase perfeitamente neutra, nos nossos termos, esse parágrafo inteiro.

\section{$* * *$}

Se certo pudor poderia até me levar a retoricamente pedir desculpas pela extensão da análise, no fundo eu posso apenas me desculpar por não poder fazê-la mais densa. Mas, para a comparação que proponho das traduções ela há de mais que bastar. É claro que esse tipo de leitura preliminar é mais efetivo como mecanismo no que se refere ao apontamento de dados pontuais, lexicais, sonoros: pequenos desvios. É claro, também, que os padrões mais amplos (aquilo a que eu vinha me referindo como um ritmo frasal, da escala do parágrafo) tendem a depender mais diretamente, por exemplo, dos recursos de pontuação, que tendem a se manter mais ou menos inalterados em boas traduções, e que, portanto, são como que automaticamente reproduzidos no texto traduzido. Ou deveriam.

A primeira tradução de Grande sertão: veredas para o inglês, no entanto, parece dar jeito de escapar mesmo da reprodução desses efeitos que poderíamos julgar como que "automáticos".

É conhecida a resenha de William Grossman (1963), que ainda em 1963, ano da publicação de The devil to pay in the backlands, como se chamou a versão inglesa de James L. Taylor e Harriet de Onís, sintetizava o que viria a ser o tom da recepção crítica desta primeira tradução, bem intencionada (inclusive em termos de proposta editorial), mas de méritos algo questionáveis. 
Os tradutores merecem a nossa compaixão. Como é que se pode traduzir um livro em que a substância é intimamente ligada a um estilo único? Rosa por vezes emprega onomatopeias, aliterações, ritmos e até rima. Ele emprega arcaísmos, regionalismos e termos inventados; em certos trechos até brasileiros eruditos acham difícil entendê-lo. Os tradutores poderiam ter tentado criar um estilo inglês com um sabor tão próximo quanto possível do português de Rosa. O produto provavelmente teria sido ou brilhante ou desastroso. Mas preferiram usar um estilo convencional, o que acabou resultando no fato de que boa parte do colorido do texto se esvaiu. [...] Além disso, muitos trechos foram omitidos na tradução. O que restou, apesar de não fazer justiça a Rosa, ainda é uma obra literária de vulto (GROSSMAN, 1963). ${ }^{8}$

Não teríamos espaço, aqui, para entrar na discussão do histórico do desenvolvimento desta tradução, nem da ambígua relação de Rosa com seus tradutores (não apenas os americanos), que sistematicamente parece mais pautada por um desejo desmedido de ver a obra publicada (divulgada) nos mais vários mercados do que por qualquer obsessão detalhista ou "protecionista". 9 "

Ao texto: veja-se como seria possível defender a tradução em questão.

\footnotetext{
8 "The translators deserve our sympathy. How can one translate a book in which the substance is closely wed to a unique style? Rosa sometimes employs onomatopoeia, alliteration, rhythm and even rhyme. He uses archaisms, regional expressions and terms of his own fabrication; in some passages even erudite Brazilians find him hard to understand. The translators might have tried to devise an English style with a flavor as close to that of Rosa's Portuguese as possible. The product would probably have been either brilliant or disastrous. They chose, instead, to employ a conventional style, wit the result that much of the color is drained from the book. (For example, where Rosa writes of the "foamy spit" on the surface of swollen, dirty rivers, the translators merely write "spume.") Also, many passages have been omitted in the translation. What remains, although it does not do Rosa justice, is still an impressive piece of literature" (Tradução minha).

${ }^{9}$ Cf. para isso textos como o de Armstrong (2001).
} 
Nonought. Those shots you heard were not men fighting. God be praised. It was just me there in the back yard, target-shooting down by the creek, to keep in practice. I do it every day, because I enjoy it; [Ø] have ever since I was a boy. Afterwards, they came to me about a calf, a stray white one, with the queerest eyes, and a muzzle like a dog. They told me about it but I didn't want to see it. On account of the deformity it was born with, with lips drawn back, it looked like somebody laughing. Man-face or dogface: that settled it for them; it was the devil. Foolish folk. They killed it. Don't know who it belonged to. They came to borrow my gun and I let them have it.

You are smiling, amused-like. Listen, when it is a real gunfight, all the dogs start barking, immediately — then when it's over you go to see if anybody got killed. You will have to excuse it, sir, but this is the sertão. Some say it's not - that the real sertão is way out yonder, on the high plains, beyond the Urucúia River. Nonsense. For those of Corinto and Curvelo, then, isn't right here the sertão? Ah, but there's more to it than that! The sertão describes itself: it is where the grazing lands have no fences; where you can keep going ten, fifteen leagues without coming upon a single house; where a criminal can safely hide out, beyond the reach of the authorities. The Urucuiia rises in the mountains to the west. But today, on its banks, you find everything: huge ranches bordering rich lowlands, the flood plains; farms that stretch from woods to woods; thick trees in virgin forests - some are still standing. The surrounding lands are the gerais. These gerais are endless. Anyway, the gentleman knows how it is: each one believes what he likes: hog, pig, or swine, it's as you opine. The sertão is everywhere (ROSA, 1963, grifos meus).

Pode-se comentar o quanto se quiser (tentei marcar apenas em negrito as raras e ralas marcas de qualquer tentativa de "desvio", de se "marcar" o texto como não padrão), mas trata-se de um massacre. A começar, inclusive, das questões mais pretensamente estáveis. A pontuação foi completamente alterada. A paragrafação mudou. Todo 
o tom de oralidade e de invenção simplesmente some, em prol do que uma leitura mais "generosa" poderia considerar uma estratégia vernacularizadora radical, "reader friendly", como quer, por exemplo, Krause (2010, p. 232), que de fato faz questão de sublinhar que essa estratégia seria resultado das intervenções não apenas dos dois tradutores, mas também da editora e do próprio Rosa.

Já houve quem dissesse que a tentativa ali foi se aproximar de padrões genéricos vernáculos dos Estados Unidos. Ou seja, transformar Grande sertão:veredas em um romance de caubóis. Mas mesmo Faulkner e, ainda posteriormente, Cormac McCarthy podem provar que esse gênero também não precisa prescindir de invenção. Mas, aqui, o que temos é, mais que uma estratégia domesticadora, no sentido que normalmente se dá ao termo nos estudos da tradução (seja em Schleiermacher seja em Venuti), uma "estratégia", domadora, amansadora, que pretendeu (e conseguiu) retirar do texto quase tudo que ele tinha de arisco, de arriscado.

Compare-se, no entanto, aquele texto (em cuja análise definitivamente não parece que tenha material para me estender) com a proposta de tradução ainda em curso de Alison Entrekin, publicada recentemente na revista Words Without Borders. ${ }^{10}$

Nonought. [Ø]Shots you heard weren’t a shootout, God be. I was training sights on trees in the backyard, at the bottom of the creek. Keeps my aim good. [Ø]Do it every day, I enjoy it; [Ø] have since the tenderest age. Anyhow, [Ø]folks came calling. Bout a calf: white one, strayling, eyes like no thing ever seen and a dog's mask. They told me; I didn't want to see. [Ø]Seems it was defective from birth, lips curled back, and looked to be laughing, personlike. Human face, hound face: they decided - it was the devil. Oafenine bunch. They killed it. Nought a clue bout the owner. They came to beg my guns, I let em. I'm not superstitious. You got a way of laughing, sir... Look: when shots are for real, first the dogs set up barking, that instant - then you go see if anyone's dead. Don't mind, sir, this is the sertão. Some reckon it in't: the backlands

\footnotetext{
${ }^{10}$ Por mera economia de espaço e pela facilidade de apresentação, mostro o texto de Entrekin já com os destaques em negrito que podem corresponder a momentos de algum tipo de marca, de desvio dos padrões literários ou "cultos" do inglês.
} 
are further off, they say, the campos-gerais inside and out, back-o-beyond, high plains, [Ø]far side of the Urucúia. Lottarot. To folks in Corinto and Curvelo, in't this here the sertão? Ah, and that's not all! The sertão makes itself known: it's where pastures have no fences, they say; where a man can go fifteen, twenty miles without coming to a single house; where outlaws live out their hallelujah, in the yonder beyond the law. The Urucúia comes from the highlands in the west. But nowadays, all long the riverrun, there's everything — walloping great farms, lushlands bordering banks, the floodplains; crops that go from wood to wood, thickset trees, even some virgin forest. All round is Minas Gerais. These gerais have no bounds. Anyway, you know it is, sir, to each his own: cows or kine, depend on your eyen... The backlands are everywhere (ROSA, 2016, negritos meus).

Mesmo essa simples exposição do trecho com marcas (sempre com algum grau de subjetividade) já sublinha a diferença, digamos, quantitativa entre as duas propostas de tradução. Acrescente-se ainda a habilidade da tradutora em lidar com a inserção dos termos "novos" para um leitor anglófono: tanto os "campos gerais" quanto a famosa dificuldade da palavra "sertão"... os dois casos recebem como que "glosas" intratextuais, paralelas, que possibilitam simultaneamente a estrangeirização (a apresentação do termo novo ao leitor de língua inglesa) e certo grau de domesticação pela introdução do paralelo, seja com um termo razoavelmente conhecido, como quando se emparelha a primeira ocorrência de "sertão" com sua "tradução" por backlands, seja com um termo geográfico mais estável, mais consultável, como quando da introdução do topônimo pleno "Minas Gerais" junto da ocorrência de "os gerais", no original.

É bem verdade que se pode argumentar que nem no livro nem na geografia popular há plena identidade biunívoca entre a região dos Gerais e o estado de Minas Gerais. Mas ao menos neste momento (estamos na abertura do romance) parece que essa ligeira relativização banca seu preço, possibilitando que um leitor estrangeiro se situe mais velozmente no texto.

E, além do mero número de marcas de estranhamento e de desvio, perceba-se o "tipo" dessas alterações. A tão típica (no original) supressão 
do artigo definido, várias supressões de pronomes sujeito (muito mais "marcadas" em inglês: língua de sujeito obrigatório), regionalismos, marcas de pronúncia, hapax legomena (lottarot?), arcaísmos (kine-eyen), felizes espelhamentos (hallelujah por "cristo-jesus"), contrações atípicas (como naquele in 't, que evita o comum isn't sem incorrer no americanismo mais nítido de ain 't). Marcas variadas, que tanto usam recursos típicos do inglês quanto forçam a língua a se estrangeirificar e, ainda, empregam possibilidades mais radicais exclusivamente suas.

Estaria aqui o inglês "com um sabor tão próximo quanto possível do original de Rosa” que Grossman (1963) alertava poder ser bênção e danação?

Para determinarmos, talvez valha a pena sublinhar que, além das eventuais correspondências pontuais, além do mero número das manipulações de superfície, que de fato se aproxima mais daquilo que pude constatar na leitura mais cerrada do original de Rosa, resta analisar na proposta de Entrekin (além de tudo cerradamente fiel ao que me pareceria incontornável na esfera da pontuação e da paragrafação, fato que, como vimos, merece realmente comentário, dada a solerte desfaçatez com que os outros tradutores trataram essa estrutura subjacente, que deveria parecer inamovível) o elemento talvez mais valioso e, ao mesmo tempo, mais difícil de se expor em análises que pretendam de alguma maneira quantificar, isolar, destacar os dados que apontam para a qualidade de um texto final.

Trata-se do fato de que o texto de Entrekin é incrivelmente cuidado, bem realizado e bem-sucedido em inglês.

A condução da sintaxe, a inserção das marcas de oralidade e de "estranheza", tudo se dá pautado não apenas por uma eventual correspondência ponto a ponto com o original (onde se poderia pensar algo simplisticamente que todas as marcas deveriam ser equivalentes em todos os critérios: tipo, grau de desvio e, pior ainda, ponto exato de inserção), mas sim por uma extrema atenção às especificidades da língua para a qual se traduz. E, decorrente disso, de uma extrema atenção ao resultado estético final.

Veja-se o mesmo trecho, agora com os destaques em negrito não nos desvios de padrão literário-linguístico, mas nos momentos em que o texto chama a atenção para a superfície como que poética (sonora) de sua composição. 
Nonought. Shots you heard weren't a shootout, God be. I was training sights on trees in the backyard, at the bottom of the creek. Keeps my aim good. Do it every day, I enjoy it; have since the tenderest age. Anyhow, folks came calling. Bout a calf: white one, strayling, eyes like no thing ever seen and a dog's mask. They told me; I didn't want to see. Seems it was defective from birth, lips curled back, and looked to be laughing, person-like. Human face, hound face: they decided - it was the devil. Oafenine bunch. They killed it. Nought a clue bout the owner. They came to beg my guns, I let em. I'm not superstitious. You got a way of laughing, sir... Look: when shots are for real, first the dogs set up barking, that instant — then you go see if anyone's dead. Don't mind, sir, this is the sertão. Some reckon it in't: the backlands are further off, they say, the campos-gerais inside and out, back-o-beyond, high plains, far side of the Urucúia. Lottarot. To folks in Corinto and Curvelo, in't this here the sertão? Ah, and that's not all! The sertão makes itself known: it's where pastures have no fences, they say; where a man can go fifteen, twenty miles without coming to a single house; where outlaws live out their hallelujah, in the yonder beyond the law. The Urucúia comes from the highlands in the west. But nowadays, all long the riverrun, there's everything walloping great farms, lushlands bordering banks, the floodplains; crops that go from wood to wood, thickset trees, even some virgin forest. All round is Minas Gerais. These gerais have no bounds. Anyway, you know it is, sir, to each his own: cows or kine, depend on your eyen... The backlands are everywhere (ROSA, 2016, megritos meus).

Inúmeras sequências métricas (breves, como deveriam ser), de pés trocaicos, anapésticos, jâmbicos e peônicos terceiros cuja variação garante a presença constante de efeitos de ritmo sem criar uma cadência dominante que apagasse o prosaísmo do trecho; simetrias sonoras consonantais e vocálicas (dentre elas trechos quase de eco, como em yonder beyond); rimas e quase-rimas.

Como se não bastasse, em termos de usos do material específico da língua de chegada, a tradutora ainda insere uma breve alusão (riverrun) 
ao Finnegans wake, de James Joyce, irmão próximo da cruzada rosiana.

Daquela primeira palavra do parágrafo, aqui recriada em sua familiaridade/estranhamento, passando pela coincidência do grau de diferença e leve desvio em training sights e pelas numerosas supressões de pronomes e artigos e inclusões de dado oral (mais ativamente empenhadas, aqui, em reproduzir a efetiva pronúncia, praxe muito mais consolidada e menos estereotipada na tradição literária anglófona), incluindo a variação de registros e inclusive de fontes geográfico-diacrônicas para o seu vocabulário (do belo oafenine ao quase americanismo de reckon), o que vemos é um texto que se esforça por responder quantitativamente à intensidade da manipulação da superfície do original de Rosa, ao mesmo tempo em que obtém grande sucesso ao se "investir" de uma postura não necessariamente reprodutora, mas "equivalente" à do original.

Entrekin pode correr o risco do fracasso, mas ao menos corre o risco. Ela está no que me parece ser a mais certeira das rotas rumo ao sucesso num projeto de tradução do alcance e da envergadura que merece ter uma nova versão inglesa de Grande sertão: veredas: o risco, coragem.

Sempre haverá perdas, e a tradutora deve ser mesmo a primeira a reconhecê-las e lamentá-las. Foi-se aquele eufemismo inaugural da longa lista de nomes do inominável satanás. Ao mesmo tempo, no entanto, aquele "I let em", onde a não especificação do referente do anafórico e mesmo a frágil ligação semântica entre os verbos to beg e to let abrem espaço à mesmíssima ambiguidade que já havíamos apontado no original de Rosa, é um sucesso felicíssimo.

Sempre haverá ganhos, e todo o voo abarrocado de Riobaldo em sua descrição do sertão encontra não apenas espelhamento, mas irmanamento em uma poética profundamente germânica, com ênfase em figuras de aliteração e de células métricas recorrentes.

$* * *$

É pouco provável que mesmo com a restrição estabelecida pela dimensão reduzida do corpus analisado tenha sido possível se atingir qualquer coisa remotamente semelhante ao grau de confiabilidade que Paulo Henriques Britto pretende alcançar, e tantas vezes alcança. Mas acredito que a proposta de uma análise da tradução de prosa literária nos moldes aqui meramente esboçados, e esboçados no confronto com um texto tão central, pode e pôde justificar seus possíveis méritos. 
Por outro lado, sei que comecei esta análise propondo certa quantificação, ou a possibilidade de uma análise objetiva, objetivável das traduções inglesas de Grande sertão: veredas. Sei também que o espaço de um texto como este jamais bastaria para uma análise detida e pontual de cada ocorrência, que além de tudo provavelmente teria pouco interesse para um leitor que não estivesse, ele mesmo, envolvido com a prática da tradução.

Mas acredito ter como que "feito por merecer", depois do levantamento mais ou menos detalhado de ocorrências, depois de uma análise em alguma medida calcada em exemplos ancorados na materialidade do texto, contestáveis até por terem sido apresentados isoladamente, e alicerçados em questões mais amplas de padrões sociolinguísticos (desvios regionalizantes e diastráticos) e literários (desvios de tipo "função poética" e de tipo retórico), certa margem de manobra, certa liberdade: a possibilidade da valorização e do destaque de um elemento menos duro, menos formalizado (ainda que igualmente formalizável) e mais característico daquilo que, resultante de todos aqueles processos analisados, mesmo no que se refere ao texto original, é, no entanto, menos quantificável, algo menos verbalizável, mas nem por isso menos perceptível, menos sensível e menos central para a apreciação do efeito literário.

$\mathrm{Eu}$, como falante nativo de português brasileiro, frequentemente me dou ao direito triunfantemente egoísta de lembrar que nenhum outro falante de outros idiomas poderá, em qualquer momento, ter o acesso direto ao texto de Rosa que temos nós. Esse prazer imediato só cabe a nós.

É claro que na mesma medida eu posso lamentar o acesso perenemente diagonal, não "cordial", não cardíaco que terei sempre ao texto do Ulysses ou do Finnegans wake.

Por outro lado, como tradutor, não deixo de valorizar o impacto direto de uma boa versão brasileira de um texto literário de qualidade, e seu também imediatismo como veículo de contato e de fruição: aquele fator que nos faz lembrar que eu, leitor brasileiro de 2016, estou mais próximo da tradução de Guerra e paz de Rubens Figueiredo do que qualquer leitor moscovita de hoje está do texto de Voina i mir de Tolstói.

Aqui, uma parcela desse efeito "imediato" e, consequentemente, daquele vicário orgulho egoísta, compete exclusivamente ao público da tradução.

E o que uma tradução como a que promete ser a versão integral de Alison Entrekin do Grande sertão: veredas agora pode me fazer sentir 
é certa inveja da relação visceral que um falante nativo de inglês terá com trechos que, a mim, já parecem comoventes.

Pois Guimarães Rosa e Riobaldo, para ele, agora se referem liricamente a:

\section{...lushlands bordering banks, the floodplains; crops that go from wood to wood, thickset trees...}

\section{Referências}

ARMSTRONG, P. Guimarães Rosa in translation: scrittore, editore, traduttore, traditore. Luso-Brasilian Review, Madison, v. 38, n. 1, p. 65-87, 2001.

BRITTO, P. H. Para uma avaliação mais objetiva das traduções de poesia. In: KRAUSE, G. B. (Org.). As margens da tradução. Rio de Janeiro: Faperj, Caetés, Uerj, 2002.

GROSSMAN, W. Outlaw with a problem. The New York Times, New York, 21 Apr. 1963.

KRAUSE, J. R. Translation and the reception and influence of Latin American literature in the United States. 2010. 275 f. Tese (Doutorado) - Graduate School, Vanderbilt University, 2010.

MESCHONNIC, H. Poética do traduzir. São Paulo: Perspectiva, 2010.

ROBSON, L. Master of reality: on Henry James' non-fiction. New Statesman, 27 Feb. 2016. Books. Disponível em: <http://www. newstatesman.com/culture/books/2016/02/master-reality-henry-jamesnon-fiction>. Acesso em: 29 fev. 2016.

ROSA, João Guimarães. Grande sertão: veredas. Rio de Janeiro: José Olympio, 1956.

ROSA, João Guimarães. Grande Sertão: Veredas (Bedeviled in the Badlands). Tradução de Alison Entrekin. Words Without Borders, July 2016. Excerto. Disponível em: <http://www.wordswithoutborders. org/article/july-2016-brazil-beyond-rio-grande-sertaeo-veredas-joaoguimaraes-rosa>. Acesso em: 29 fev. 2016.

ROSA, João Guimarães. The devil to pay in the backlands. Tradução de James L. Taylor e Harriet de Onís. Nova York: Knopf, 1963. 